\title{
High-dose-rate brachytherapy delivered in two fractions as monotherapy for low-risk prostate
}

\section{cancer}

\author{
Ricardo Cendales, MD, MSc, Elizabeth Alwers, MD, MSc, Javier Cifuentes, MD, Ivan Bobadilla, MD, Felipe Torres, MD, \\ Juan Arbelaez, MD, Armando Gaitan, MD, Helber Cortes, MSc, Yenny Acevedo, MSc, Paulo Quintero, MSc, \\ Jaider Vasquez, MSc \\ Centro de Control de Cancer Ltoa., Bogota, Colombia
}

\begin{abstract}
Purpose: High-dose-rate (HDR) brachytherapy has been accepted as an effective and safe method to treat prostate cancer. The aim of this study was to describe acute toxicity following HDR brachytherapy to the prostate, and to examine the association between dosimetric parameters and urinary toxicity in low-risk prostate cancer patients.

Material and methods: Patients with low-risk prostate cancer were given HDR brachytherapy as monotherapy in two 12.5 Gy fractions. Planning objectives for the planning target volume (PTV) were $\mathrm{V}_{100 \%} \geq 90 \%$ and $\mathrm{V}_{150 \%} \leq 35 \%$. Planning objectives for organs at risk were $V_{75 \%} \leq 1 \mathrm{cc}$ for the bladder, rectum and perineum, and $\mathrm{V}_{125 \%} \leq 1 \mathrm{cc}$ for the urethra. Toxicity was assessed three months after treatment using the Common Terminology Criteria for Adverse Events.

Results: Seventy-three patients were included in the analysis. Thirty-three patients $(45 \%)$ reported having any type of toxicity in the three months following HDR brachytherapy. Most toxicity cases (26\%) were grade 1 urinary toxicity. Mean coverage index was 0.89 and mean $\mathrm{V}_{100}$ was 88.85 . Doses administered to the urethra were associated with urinary toxicity. Patients who received more than $111.3 \%$ of the prescribed dose in $1 \mathrm{cc}$ of the urethra were four times more likely to have urinary toxicity compared to patients receiving less than $111.3 \%(\mathrm{OR}=4.71,95 \% \mathrm{CI}$ : 1.43-15.6; $p=0.011$ ).

Conclusions: High-dose-rate brachytherapy administered as monotherapy for prostate cancer proved to be a safe alternative treatment for patients with low-risk prostate cancer. Urinary toxicity was associated with the dose administered to $1 \mathrm{cc}$ and $0.1 \mathrm{cc}$ of the urethra and was remarkably inferior to the reported toxicity in similar studies.

Key words: acute toxicity, high-dose-rate brachytherapy, monotherapy, prostate cancer.

\section{Purpose}

Prostate cancer is the leading cause of cancer incidence in males and the second cause of male cancer mortality in Colombia. In 2012, 9564 cases were diagnosed in the country [1]. Radiotherapy administered as either external beam radiotherapy (EBRT), high-dose-rate (HDR) interstitial brachytherapy or a combination of both modalities is a standard of treatment for prostate cancer. High-doserate brachytherapy was initially introduced as a boost after EBRT in the treatment of prostate cancer [2-4] and recommended by both European and American associations [5-7], particularly for patients with intermediate to high risk prostate cancer. In patients with low-risk prostate cancer, HDR brachytherapy as monotherapy is con- sidered as an alternative that could be administered in shorter periods of time, with similar efficacy, better dosimetric outcomes for organs at risk, and a lower probability of inter and intra-fractional displacements in contrast to EBRT [8].

The first studies that implemented interstitial HDR brachytherapy as monotherapy for prostate cancer used between eight and nine fractions in a five-day period [9]; afterwards, four fraction schemes were implemented in a two-day period [10]. These studies allowed HDR monotherapy to be accepted as an effective and convenient method to treat prostate cancer, providing a similar biochemical control of the disease, and low toxicity to organs at risk. This therapy continued to evolve into hypofractionation using two and even single doses [11-13]. These 
schemes proved to be convenient regarding costs and hospitalization days. Recent studies have demonstrated low toxicity and adequate local tumor control of two 12.5 Gy fractions applied in a single day as monotherapy for low-risk prostate cancer $[7,9,11,12,14]$.

Clinical results in prostate cancer in Colombia have been published using permanent interstitial brachytherapy as monotherapy [15], and HDR brachytherapy either as an exclusive therapy applied in four fractions, or as a boost to EBRT applied in two fractions [16]. However, two-fraction HDR as monotherapy for prostate cancer is not yet a common practice in the country. The purpose of this study was to describe acute toxicity and examine possible associations between different dosimetric parameters and urinary toxicity in low-risk prostate cancer patients treated with exclusive HDR brachytherapy.

\section{Material and methods}

\section{Patients}

We conducted a retrospective chart review of all patients with low-risk prostate cancer (T1-T2a tumor, PSA $\leq 10 \mathrm{ng} / \mathrm{ml}$ and a Gleason score $\leq 6)$, who had been treated with HDR brachytherapy as monotherapy between August 2011 and January 2014. Patients were considered ineligible for the procedure if they had a history of transurethral resection of the prostate, an International Prostate Symptom Score $>15$, and were unable to assume the lithotomy position or had any contraindication to receive anesthesia.

\section{Implant procedure}

The procedure was performed under regional epidural anesthesia. All patients received ciprofloxacin as a prophylactic treatment. The implant was performed under trans-rectal ultrasound (TRUS) guidance using a $5 \mathrm{~mm}$ template and two fixation needles. Implant needles were placed $10 \mathrm{~mm}$ away from the urethra, and between 3-5 mm inside of the prostatic capsule in order to decrease the dose to the rectum. Seminal vesicles were not routinely implanted considering that all patients were low-risk cases. Two gold fiducial markers were implanted as a reference to verify needle position during treatment in orthogonal X-ray images. Implant needles were fixed to the template and the template was sutured to the perineum in order to reduce the probability of needle displacement between fractions. Brachytherapy was administered in two fractions of 12.5 Gy each, applied with a six-hour interval on the same day. Prior to administering brachytherapy at the second fraction, we verified needle position using orthogonal X-ray images, which were compared to the first fraction's set of images regarding needle position in relation to the gold fiducial markers. When needed, individual needles or the entire template were manually repositioned. If necessary, it was possible to reinsert the TRUS probe prior to the second application, however, this was not necessary for any patients and no treatments needed to be re-planned due to needle displacements.

\section{Volume definition, high-dose-rate planning and dosimetric measures}

Clinical target volume (CTV) was defined based on the prostatic capsule without an extra margin. The volume of the urethra was defined using contrast media prepared by combining $15 \mathrm{cc}$ of $2 \%$ lidocaine gel, $10 \mathrm{cc}$ of saline solution, and air. This contrast was then applied via a urinary catheter. The rectum, bladder, and perineum were anatomically defined. Four auxiliary planning volumes to improve treatment optimization were defined: urethra + $4 \mathrm{~mm}$, planning target volume (PTV) $+4 \mathrm{~mm}$, body minus the PTV, and perineum (Fig. 1). Inverse planning optimization based on anatomical volumes was performed using the Treatment Planning Software HDRplus 3.0 (Eckert and Ziegler BEBIG, Germany); manual optimization was employed as a complement to further improve dose coverage.

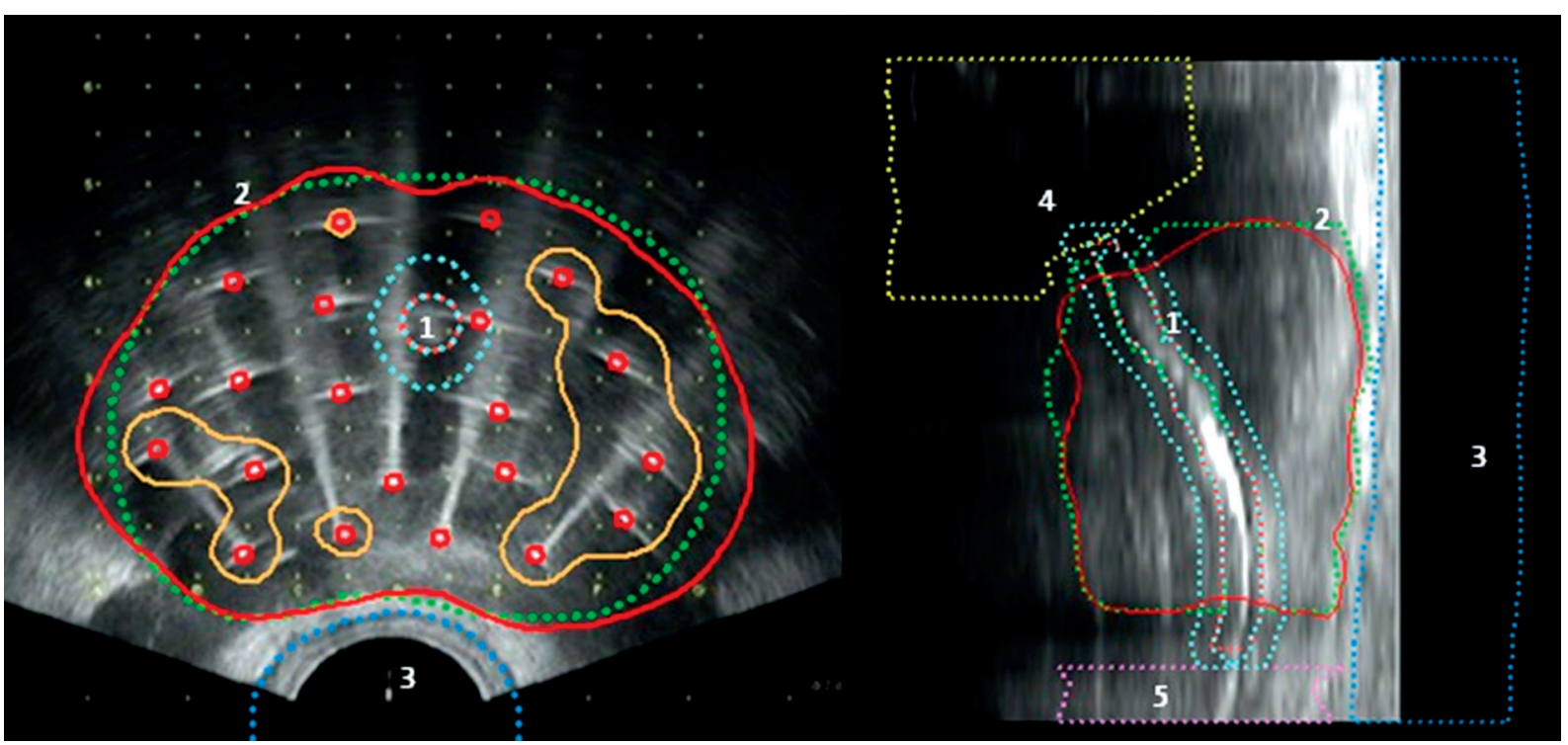

Fig. 1. Auxiliary volumes for planning optimization. Planning volumes: 1 - urethra, 2 - PTV, 3 - rectum, 4 - bladder, 5 - perineum 
Planning objectives for the PTV were $\mathrm{V}_{100 \%} \geq 90 \%$ and $\mathrm{V}_{150 \%} \leq 35 \%$. Planning objectives for organs at risk were $\mathrm{V}_{75 \%} \leq 1 \mathrm{cc}$ for the bladder, rectum and perineum, and $\mathrm{V}_{125 \%} \leq 1 \mathrm{cc}$ for the urethra. Planning target volume coverage was reported using $V_{100}$ and $D_{90}$. Planning target volume homogeneity was reported using $V_{150}$ and $V_{200}$. Coverage index $(\mathrm{CI})$, dose non-uniformity ratio (DNR), homogeneity index $(\mathrm{HI})$, and conformality number $(\mathrm{CN})$ were also reported. Dosimetry for organs at risk included the $\mathrm{V}_{75}, \mathrm{~V}_{115}, \mathrm{~V}_{125}$, as well as the $\mathrm{D}_{1 \mathrm{cc}}$ and $\mathrm{D}_{0.1 \mathrm{cc}}$.

\section{Toxicity assessment}

According to our institution's treatment guidelines, patients attended an immediate control appointment during the first week after the procedure; follow-up visits were scheduled three months after treatment. Acute toxicity was evaluated during these visits. We included all events that occurred during the previous three months, even if these had resolved before the control visit. Common Terminology Criteria for Adverse Events version 4.03 [17] was used to evaluate and describe the proportion of patients presenting symptoms related to urinary, sexual or rectal acute toxicity, and to score its severity.

\section{Statistical analysis}

Acute urinary, rectal, and sexual toxicity were described using simple frequencies and proportions. Coverage, homogeneity, dosimetric indexes, and dosimetry for organs at risk were described using central tendency and dispersion measures. Associations between dosimetry and urinary toxicity were explored by several univariable logistic regression models, in which the dependent variable was the presence or absence of urinary toxicity, and the independent variables were several dosimetric indexes. Continuous numerical variables related to coverage, homogeneity, dosimetric indexes, and dosimetry for organs at risk were categorized into binary variables prior to their inclusion in the univariable model. Categorization into binary variables was performed based on the analysis of the receiver operating characteristic (ROC) curves produced for each dosimetric parameter, in order to identify the best cutoff point (the point showing the

Table 1. Acute toxicity event distribution

\begin{tabular}{llc} 
Type of toxicity & Grade & $n(\%)$ \\
\hline Urinary & None & $50(68.5)$ \\
\cline { 2 - 3 } & Grade 1 & $19(26.0)$ \\
\cline { 2 - 3 } & Grade 2 & $3(4.11)$ \\
\cline { 2 - 3 } & Grade 3 & $1(1.37)$ \\
\hline Rectal & None & $71(97.3)$ \\
\cline { 2 - 3 } & Grade 1 & 2(2.7) \\
\hline Sexual & None & $61(83.6)$ \\
\cline { 2 - 3 } & Grade 1 & $5(6.9)$ \\
\cline { 2 - 3 } & Grade 2 & $7(9.6)$
\end{tabular}

Toxicity was evaluated using CTCAE v.4.03. better compromise between sensitivity, specificity, percentage of correctly classified cases, and area under the curve [AUC]). Variables that did not have a clear cut-off point on the ROC curve were analyzed as continuous numeric variables. Odds ratios and 95\% confidence intervals were obtained from each univariable logistic regression model. Wald tests were used to calculate $p$-values to test for the general association between each variable and urinary toxicity. All statistical analyses were carried out using STATA/SE version 12.1 (College Station, TX: StataCorp LP, USA).

\section{Results}

Between August 2011 and January 2014, a total of 92 patients with low-risk prostate cancer were treated with HDR brachytherapy as monotherapy for prostate cancer at our institution. Seventeen patients were excluded from the study because they did not attend the follow-up visit; another two patients were excluded because of lack of information on some dosimetric parameters; thus, the final analysis consisted of 73 patients. Mean age was 65.5 years, mean number of needles was 15.4, and the mean prostate volume was $44.9 \mathrm{cc}$. Thirty-three patients $(45.2 \%)$ reported having any type of toxicity in the three months after receiving HDR brachytherapy. Most of the toxicity was grade 1 urinary toxicity (Table 1 ).

Mean coverage index, mean $\mathrm{D}_{90}$, and mean $\mathrm{V}_{100}$ showed a satisfactory coverage of the treatment volume. Mean HI, mean $\mathrm{V}_{150}$, and mean $\mathrm{V}_{200}$ showed that heterogeneity was well controlled. Dosimetry for organs at risk showed that the planning objectives were achieved for most patients (Table 2).

The ROC analysis allowed us to categorize most of the numerical dosimetrical indexes (Table 3). The indexes that showed the highest AUC were urethra $\mathrm{V}_{115 \%}$ with a cutoff point of $5.9 \%$, urethra $\mathrm{D}_{0.1 \mathrm{cc}}$ with a cutoff point of $117.4 \%$, and urethra $\mathrm{D}_{1 \mathrm{cc}}$ with a cutoff point of $111.3 \%$. None of the bladder indexes showed a high AUC or a clear cut-off point. This analysis allowed us to decide on the best cut-off value for each variable before entering it in the regression model for analysis. Based on the logistic regression analysis, we found that the doses administered to the urethra were associated with urinary toxicity. Patients who received more than $111.3 \%$ of the prescribed dose in $1 \mathrm{cc}$ of the urethra were four times more likely to have urinary toxicity compared to patients receiving less than $111.3 \%$ $(\mathrm{OR}=4.71,95 \% \mathrm{CI}: 1.43-15.6 ; p=0.011)$. Similarly, patients who received more than $117.4 \%$ of the prescribed dose in $0.1 \mathrm{cc}$ of the urethra had a higher risk of urinary symptoms compared to those who received less than $117.4 \%$ (OR $=$ 2.76, 95\% CI: 1.00-7.63; $p=0.05$ ) (Table 4).

\section{Discussion}

High-dose-rate brachytherapy administered as monotherapy in two fractions of 12.5 Gy showed to be a safe treatment for patients with low-risk prostate cancer. This treatment alternative comprises advantages related with the reduction of hospitalization costs, caregiver, and administrative burden, as well as patient comfort. 
Table 2. Coverage, homogeneity and dosimetry for organs at risk

\begin{tabular}{|c|c|c|c|c|c|}
\hline Variable & Mean & SD & $10^{\text {th }}$ percentile & Median & $90^{\text {th }}$ percentile \\
\hline $\mathrm{Cl}$ & 0.89 & 0.03 & 0.86 & 0.90 & 0.92 \\
\hline DNR & 0.39 & 0.06 & 0.30 & 0.39 & 0.46 \\
\hline $\mathrm{HI}$ & 0.54 & 0.06 & 0.47 & 0.54 & 0.64 \\
\hline $\mathrm{CN}$ & 0.66 & 0.08 & 0.55 & 0.68 & 0.75 \\
\hline \multicolumn{6}{|l|}{ PTV } \\
\hline $\mathrm{V}_{100}(\%)$ & 88.85 & 2.95 & 85.60 & 89.70 & 91.90 \\
\hline $\mathrm{V}_{150}(\%)$ & 34.72 & 5.61 & 27.50 & 34.50 & 41.50 \\
\hline$V_{200}(\%)$ & 12.62 & 3.46 & 8.20 & 12.10 & 16.80 \\
\hline $\mathrm{D}_{90}(\%)$ & 97.79 & 5.34 & 92.10 & 99.40 & 103.0 \\
\hline \multicolumn{6}{|l|}{ Urethra } \\
\hline $\mathrm{V}_{115}(\%)$ & 13.16 & 14.92 & 0.10 & 7.10 & 33.70 \\
\hline $\mathrm{V}_{125}(\%)$ & 0.65 & 2.73 & 0.00 & 0.00 & 0.60 \\
\hline $\mathrm{D}_{1 \mathrm{cc}}(\%)$ & 97.68 & 18.42 & 69.20 & 105.50 & 113.10 \\
\hline $\mathrm{D}_{0.1 c c}(\%)$ & 115.75 & 5.45 & 108.50 & 115.70 & 122.20 \\
\hline \multicolumn{6}{|l|}{ Bladder } \\
\hline $\mathrm{V}_{75}(\%)$ & 0.26 & 0.36 & 0.00 & 0.10 & 0.80 \\
\hline $\mathrm{D}_{1 \mathrm{cc}}(\%)$ & 59.59 & 6.34 & 52.40 & 59.80 & 67.20 \\
\hline $\mathrm{D}_{0.1 c c}(\%)$ & 72.45 & 7.96 & 60.60 & 72.00 & 81.00 \\
\hline \multicolumn{6}{|l|}{ Rectum } \\
\hline$V_{75}(\%)$ & 2.01 & 2.64 & 0.10 & 1.10 & 4.90 \\
\hline $\mathrm{D}_{1 \mathrm{cc}}(\%)$ & 68.85 & 6.24 & 62.00 & 69.30 & 75.70 \\
\hline $\mathrm{D}_{0.1 \mathrm{cc}}(\%)$ & 80.29 & 6.96 & 72.10 & 80.80 & 87.60 \\
\hline
\end{tabular}

SD - standard deviation, Cl - coverage index, DNR - dose non-uniformity ratio, HI - homogeneity index, CN - conformality number, PTV-planning target volume

Table 3. Cut-off values chosen for each variable based on sensitivity, specificity and AUC

\begin{tabular}{lcccc} 
Variable & Sensitivity & Specificity & AUC & Cut-off point \\
\hline Prostate volume (cc) & 82.61 & 40 & 0.531 & 35.8 \\
\hline Cl & 86.96 & 24 & 0.458 & 0.87 \\
\hline DNR & 52.17 & 56 & 0.547 & 0.40 \\
\hline$H I$ & 78.26 & 32 & 0.446 & 0.51 \\
\hline CN & & & 0.433 & 88.9 \\
\hline PTV & & & 0.490 & 35.3 \\
\hline$V_{100}^{*}(\%)$ & 73.91 & 42 & 0.529 & 5.9 \\
\hline$V_{150}(\%)$ & 52.17 & 58 & 0.500 & 111.3 \\
\hline$V_{200}(\%)^{*}$ & & & 0.620 & 117.4
\end{tabular}

*Those variables that did not have a clear cut-off point on the ROC curve were analyzed as continuous variables and only the corresponding AUC is presented. $A U C$ - area under the curve, $\mathrm{Cl}$-coverage index, DNR - dose non-uniformity ratio, $\mathrm{HI}$ - homogeneity index, $\mathrm{CN}$ - conformality number

In comparison with low-dose-rate brachytherapy, HDR is a more economical alternative $[18,19]$, with a greater potential of obtaining better dosimetric results, and with an even greater possibility to obtain dosimetric advantages regarding coverage, conformity, homogeneity, and dosage to healthy organs since the advent of inverse planning algorithms and optimization based in anatomical structures instead of geometric structures [20,21]. 
Table 4. Association between selected dosimetric parameters and urinary toxicity

\begin{tabular}{|c|c|c|c|c|c|c|}
\hline \multirow[t]{2}{*}{ Parameter } & & \multicolumn{2}{|c|}{ Urinary toxicity } & \multirow[t]{2}{*}{$O R^{*}$} & \multirow[t]{2}{*}{$95 \% \mathrm{Cl}$} & \multirow[t]{2}{*}{$p$-value } \\
\hline & & $\begin{array}{c}\text { Yes } \\
n(\%)\end{array}$ & $\begin{array}{c}\text { No } \\
n(\%)\end{array}$ & & & \\
\hline \multicolumn{7}{|l|}{ Age (years) } \\
\hline & $50-60$ & $3(18.75)$ & $13(81.25)$ & 1 & & \multirow[t]{4}{*}{0.631} \\
\hline & $61-65$ & $6(37.50)$ & $10(62.50)$ & 2.60 & $0.52-13.04$ & \\
\hline & $66-69$ & $7(33.33)$ & $14(66.67)$ & 2.17 & $0.46-10.20$ & \\
\hline & $\geq 70$ & $7(35.00)$ & $13(65.00)$ & 2.33 & $0.49-11.06$ & \\
\hline \multicolumn{7}{|c|}{ Number of needles } \\
\hline & $9-15$ & 11 (w28.95) & 27 (71.05) & 1 & & \multirow[t]{2}{*}{0.624} \\
\hline & $16-20$ & $12(34.29)$ & $23(65.71)$ & 1.28 & $0.47-3.44$ & \\
\hline \multicolumn{7}{|c|}{ Prostate volume (cc) } \\
\hline & $<35.8$ & $4(16.67)$ & $20(83.33)$ & 1 & & \multirow[t]{2}{*}{0.064} \\
\hline & $\geq 35.8$ & 19 (38.78) & $30(61.22)$ & 3.17 & $0.94-10.7$ & \\
\hline \multicolumn{7}{|l|}{$\mathrm{Cl}(\%)$} \\
\hline & $<87$ & $3(20.00)$ & $12(80.00)$ & 1 & & \multirow[t]{2}{*}{0.289} \\
\hline & $\geq 87$ & $20(34.48)$ & $38(65.52)$ & 2.11 & $0.53-8.34$ & \\
\hline \multicolumn{7}{|l|}{ DNR (\%) } \\
\hline & $<40$ & $11(28.21)$ & $28(71.79)$ & 1 & & \multirow[t]{2}{*}{0.516} \\
\hline & $\geq 40$ & $12(35.29)$ & $22(64.71)$ & 1.39 & $0.52-3.74$ & \\
\hline \multicolumn{7}{|l|}{$\mathrm{HI}(\%)$} \\
\hline & $<51$ & $5(23.81)$ & $16(76.19)$ & 1 & & \multirow[t]{2}{*}{0.371} \\
\hline & $\geq 51$ & $18(34.62)$ & $34(65.38)$ & 1.69 & $0.53-5.37$ & \\
\hline \multicolumn{7}{|l|}{ PTV } \\
\hline \multirow[t]{2}{*}{$V_{100}(\%)$} & $<88.9$ & $6(22.22)$ & $21(77.78)$ & 1 & & \multirow[t]{2}{*}{0.195} \\
\hline & $\geq 88.9$ & 17 (36.96) & $29(63.04)$ & 2.05 & $0.69-6.08$ & \\
\hline \multirow[t]{2}{*}{$V_{150}(\%)$} & $<35.3$ & $11(27.50)$ & $29(72.50)$ & 1 & & \multirow[t]{2}{*}{0.418} \\
\hline & $\geq 35.3$ & $12(36.36)$ & $21(63.64)$ & 1.51 & $0.56-4.06$ & \\
\hline \multicolumn{7}{|l|}{ Urethra } \\
\hline \multirow[t]{2}{*}{$V_{115}(\%)$} & $<5.9$ & 7 (20.59) & 27 (79.41) & 1 & & \multirow[t]{2}{*}{0.065} \\
\hline & $\geq 5.9$ & $16(41.03)$ & $23(58.97)$ & 2.68 & $0.94-7.65$ & \\
\hline \multirow[t]{2}{*}{$\mathrm{D}_{1 \mathrm{cc}}(\%)$} & $<111.3$ & $14(24.14)$ & $44(75.86)$ & 1 & & \multirow[t]{2}{*}{0.011} \\
\hline & $\geq 111.3$ & $9(60.00)$ & $6(40.00)$ & 4.71 & $1.43-15.6$ & \\
\hline \multirow[t]{2}{*}{$\mathrm{D}_{0.1 \mathrm{cc}}(\%)$} & $<117.4$ & $10(22.73)$ & 34 (77.27) & 1 & & \multirow[t]{2}{*}{0.050} \\
\hline & $\geq 117.4$ & $13(44.83)$ & $16(55.17)$ & 2.76 & $1.00-7.63$ & \\
\hline
\end{tabular}

${ }^{*}$ ORs based on univariable logistic regression models.

OR - odds ratio, 95\% Cl-95\% confidence intervals, p-values from Wald tests, HI - homogeneity index, Cl-coverage index, DNR - dose non-uniformity ratio

The observed grade 2 acute urinary toxicity in our study is remarkably lower than that reported in similar studies. Even though these studies used different scales to assess toxicity, we consider it to be a valid comparison when evaluating toxicity in different hypofractionation schemes. A similar finding is related to rectal toxicity, which was lower in our study in comparison with other studies (Table 5). However, sexual toxicity was higher in our study, although a caveat to this regard is that sexual toxicity was not routinely evaluated in the other series.

The remarkably lower toxicities observed in our study could be related to a relatively low dose administered to the PTV, considering that the mean $\mathrm{V}_{100 \%}$ was $88.8 \%$, and that even the $90^{\text {th }}$ percentile for $V_{100 \%}$ was of $91.9 \%$. Our coverage could be better considering that most of the studies using pre-planning and inverse planning optimi- 
Table 5. Toxicity reported with the use of HDR brachytherapy in recent studies

\begin{tabular}{lccccccc} 
Study (ref.) & Year & $n$ & $\begin{array}{c}\text { Dose/fraction } \\
\text { (Gy) }\end{array}$ & Fractions & $\begin{array}{c}\text { Grade 2 urinary } \\
\text { toxicity (\%) }\end{array}$ & $\begin{array}{c}\text { Grade 1 rectal } \\
\text { toxicity (\%) }\end{array}$ & $\begin{array}{c}\text { Grade 1 sexual } \\
\text { toxicity (\%) }\end{array}$ \\
\hline Present study & 2015 & 73 & 12.5 & 2 & 4.1 & 2.7 & 6.9 \\
\hline Demanes [22] & 2011 & 298 & $7 / 9.5$ & $6 / 4$ & 10.0 & 1.0 & - \\
\hline Yoshioka [23] & 2011 & 112 & 6 & 9 & 16.9 & - & - \\
\hline Ghilezan [11] & 2012 & 99 & 13.5 & 2 & 21.2 & 8.3 & - \\
\hline Hoskin [12] & 2012 & 33 & 13 & 2 & 21 & 6.0 & - \\
\hline Barkati [24] & 2012 & 73 & $10 / 11.5$ & $3 / 3$ & 16.4 & 24.6 & - \\
\hline Zamboglou [25] & 2013 & 718 & $9.5 / 11$ & $4 / 3$ & $15.6-17.6$ & $12.3-18.4$ & -
\end{tabular}

Gy - Gray

zation based on anatomical volumes obtain mean $\mathrm{V}_{100 \%}$ values superior to $95 \%$. It is possible that in the scenario of current practice, in which traditional dose constraints are more easily accomplished due to better technology, modified constraints could be considered such as urethra $\mathrm{V}_{115} \leq 6 \%$, urethra $\mathrm{D}_{1 \mathrm{cc}} \leq 110 \%$, and urethra $\mathrm{D}_{0.1 \mathrm{cc}} \leq 118 \%$ in order to decrease urinary toxicity. We obtained a decreased toxicity but with a coverage that could be better. However, $\mathrm{D}_{90}$ and $\mathrm{V}_{100}$ accomplished RTOG recommendations. Consequently, we consider that long-term outcomes related to biochemical control or survival free of metastases will not be compromised. In our practice, we will consider to increase PTV coverage, and further decrease the $\mathrm{V}_{115} \leq 6 \%, \mathrm{D}_{1 \mathrm{cc}} \leq 110 \%$, and $\mathrm{D}_{0.1 \mathrm{cc}} \leq 118 \%$ for the urethra.

The study has a main limitation related to the size of the sample of patients, which is small; hence, the statistical power can only detect relatively big differences. The proportion of patients who did not attend the follow-up visit was considerable; this may have resulted in an underestimation of toxicity if the reason why patients did not attend was related to their disease. However, we did not evaluate why patients did not attend follow-up and are not able to draw any conclusions about loss to follow-up. The reduced sample size did not allow us to perform a multivariable analysis capable of controlling for confounding between the dosimetric indexes reported for urethra and some other variables such as prostate volume or heterogeneity. Future studies in our institution will consider the analysis of late toxicity and outcomes related with biochemical failure in a greater number of patients. The ROC analysis is regarded as a strength of the statistical analysis, since we were able to choose the most appropriate cut-off points before categorizing each numerical variable.

\section{Conclusions}

High-dose-rate brachytherapy as monotherapy for prostate cancer administered in two 12.5 Gy fractions proved to be a safe treatment alternative in the treatment of selected patients with low risk cancer, in the era of inverse planning optimization based on anatomical volumes. Future studies should consider increasing the PTV coverage when using inverse planning optimization based on anatomical volumes, and should consider limiting the doses administered to the $\mathrm{V}_{115}, \mathrm{D}_{1 \mathrm{cc}}$ and $\mathrm{D}_{0.1 \mathrm{cc}}$ in the urethra.

\section{Acknowledgements}

The authors would like to acknowledge the collaboration of all health and technical staff at Centro de Control de Cancer Ltda.

\section{Disclosure}

Authors report no conflict of interest.

\section{References}

1. Ferlay J, Soerjomataram I, Ervik M et al. GLOBOCAN 2012. Cancer Incidence and Mortality Worldwide. IARC CancerBase No. 11. International Agency for Research on Cancer, Lyon 2013. Available at: http://globocan.iarc.fr

2. Galalae RM, Kovács G, Schultze J et al. Long-term outcome after elective irradiation of the pelvic lymphatics and local dose escalation using high-dose-rate brachytherapy for locally advanced prostate cancer. Int J Radiat Oncol Biol Phys 2002; 52: 81-90.

3. Mate TP, Gottesman JE, Hatton J et al. High dose-rate afterloading 192iridium prostate brachytherapy: feasibility report. Int J Radiat Oncol 1998; 41: 525-533.

4. Hijazi H, Chevallier D, Gal J et al. Prostate cancer boost using high-dose-rate brachytherapy: early toxicity analysis of 3 different fractionation schemes. J Contemp Brachytherapy 2013; 5: 203-209.

5. Aström L, Pedersen D, Mercke C et al. Long-term outcome of high dose rate brachytherapy in radiotherapy of localised prostate cancer. Radiother Oncol 2005; 74: 157-161.

6. Kovács G, Pötter R, Loch T et al. GEC/ESTRO-EAU recommendations on temporary brachytherapy using stepping sources for localised prostate cancer. Radiother Oncol 2005; 74: 137-148.

7. Yamada Y, Rogers L, Demanes DJ et al. American Brachytherapy Society consensus guidelines for high-dose-rate prostate brachytherapy. Brachytherapy 2012; 11: 20-32.

8. Yoshioka Y, Suzuki O, Otani Y et al. High-dose-rate brachytherapy as monotherapy for prostate cancer: technique, rationale and perspective. J Contemp Brachytherapy 2014; 6: 91-98.

9. Yoshioka Y, Nose T, Yoshida K et al. High-dose-rate interstitial brachytherapy as a monotherapy for localized prostate cancer: treatment description and preliminary results of a phase I/II clinical trial. Int J Radiat Oncol Biol Phys 2000; 48: 675-681. 
10. Martinez AA, Pataki I, Edmundson G et al. Phase II prospective study of the use of conformal high-dose-rate brachytherapy as monotherapy for the treatment of favorable stage prostate cancer: a feasibility report. Int J Radiat Oncol Biol Phys 2001; 49: 61-69.

11. Ghilezan M, Martinez A, Gustavson G et al. High-dose-rate brachytherapy as monotherapy delivered in two fractions within one day for favorable/intermediate-risk prostate cancer: preliminary toxicity data. Int J Radiat Oncol Biol Phys 2012; 83: 927-932.

12. Hoskin P, Rojas A, Lowe G et al. High-dose-rate brachytherapy alone for localized prostate cancer in patients at moderate or high risk of biochemical recurrence. Int J Radiat Oncol Biol Phys 2012; 82: 1376-1384.

13. Prada PJ, Jimenez I, González-Suárez H et al. High-dose-rate interstitial brachytherapy as monotherapy in one fraction and transperineal hyaluronic acid injection into the perirectal fat for the treatment of favorable stage prostate cancer: treatment description and preliminary results. Brachytherapy 2012; 11: 105-110.

14. Yoshioka Y, Yoshida K, Yamazaki H et al. The emerging role of high-dose-rate (HDR) brachytherapy as monotherapy for prostate cancer. J Radiat Res 2013; 54: 781-788.

15. Cavelier L, Cantillo C, Varela E. Braquiterapia en cáncer de próstata: Implante de semillas permanentes de Iodo 125. Rev Urol Colomb 2003; 12: 7-30.

16. Ospino R, Cendales R, Alonso C. Braquiterapia de alta tasa de dosis en pacientes con cáncer de próstata. Rev Colomb Cancerol 2008; 12: 30-36.

17. National Institutes of Health, National Cancer Institute. Common Terminology Criteria for Adverse Events (CTCAE). 2010 p. Version 4.03. Available from: http://evs.nci.nih.gov/ftp1/ CTCAE/CTCAE_4.03_2010-06-14_QuickReference_5x7.pdf

18. Grills IS, Martinez AA, Hollander $\mathrm{M}$ et al. High dose rate brachytherapy as prostate cancer monotherapy reduces toxicity compared to low dose rate palladium seeds. J Urol 2004; 171: 1098-1104.

19. Martinez A, Demanes J, Vargas C et al. High-dose-rate prostate brachytherapy: an excellent accelerated-hypofractionated treatment for favorable prostate cancer. Am J Clin Oncol 2010; 33: 481-488.

20. Lachance B, Beliveau D, Lessard E et al. Early clinical experience with anatomy-based inverse planning dose optimization for high-dose-rate boost of the prostate. Int J Radiat Oncol Biol Phys 2002; 54: 86-100.

21. Akimoto T, Katoh H, Kitamoto Y et al. Anatomy-based inverse optimization in high-dose-rate brachytherapy combined with hypofractionated external beam radiotherapy for localized prostate cancer: comparison of incidence of acute genitourinary toxicity between anatomy-based inverse optimization. Int J Radiat Oncol Biol Phys 2006; 64: 1360-1366.

22. Demanes DJ, Martinez A, Ghilezan M et al. High-dose-rate monotherapy: safe and effective brachytherapy for patients with localized prostate cancer. Int J Radiat Oncol Biol Phys 2011; 81: 1286-1292.

23. Yoshioka Y, Konishi K, Sumida I et al. Monotherapeutic highdose-rate brachytherapy for prostate cancer: five-year results of an extreme hypofractionation regimen with $54 \mathrm{~Gy}$ in nine fractions. Int J Radiat Oncol Biol Phys 2011; 80: 469-475.

24. Barkati M, Williams SG, Foroudi F et al. High-dose-rate brachytherapy as a monotherapy for favorable-risk prostate cancer: a Phase II trial. Int J Radiat Oncol Biol Phys 2012; 82: 1889-1896

25. Zamboglou N, Tselis N, Baltas D et al. High-dose-rate interstitial brachytherapy as monotherapy for clinically localized prostate cancer: treatment evolution and mature results. Int J Radiat Oncol Biol Phys 2013; 85: 672-678. 